\title{
Effects of cilostazol against the progression of carotid IMT in symptomatic ischemic stroke patients
}

\author{
Sung Hyuk Heo $\cdot$ Ji Sung Lee $\cdot$ Beom Joon Kim $\cdot$ \\ Kyoung Jin Hwang $\cdot$ Jun-Hyun Kim $\cdot$ Dae-Il Chang
}

Received: 9 February 2012/Revised: 19 June 2012 / Accepted: 21 June 2012/Published online: 21 July 2012

(C) The Author(s) 2012. This article is published with open access at Springerlink.com

\begin{abstract}
Carotid intima-media thickness (IMT) is a surrogate marker for evaluating atherosclerotic vascular diseases. The phosphodiesterase inhibitor cilostazol attenuates the increase in carotid IMT in diabetes patients. We studied whether cilostazol can reduce the progression of carotid IMT in symptomatic ischemic stroke patients. From our prospective registry of acute ischemic stroke patients who were admitted during a 4.5-year period, follow-up carotid ultrasound was performed in a random sample of survivors. Patients were divided into two groups: the cilostazol group, who continued cilostazol treatment during the follow-up period; and the control group, who were prescribed antiplatelets other than cilostazol. Analysis of covariance and propensity score-matched analysis were used to evaluate the difference between groups. Among a total of 1,049 cases in our registry, 208 patients were utilized to construct two comparable sets by propensity score analysis, including 101 who received cilostazol and 107 who took antiplatelet medication without cilostazol. Both maximum and mean carotid IMT values were significantly reduced in the cilostazol group but increased in the control group (maximum left $-0.048 \pm 0.186$ vs. $0.022 \pm 0.163 \mathrm{~mm}, p=0.001$;
\end{abstract}

Electronic supplementary material The online version of this article (doi:10.1007/s00415-012-6599-y) contains supplementary material, which is available to authorized users.

S. H. Heo · K. J. Hwang · J.-H. Kim · D.-I. Chang ( $\bowtie)$ Department of Neurology, Kyung Hee University Hospital, \#1, Hoegi-dong, Dongdaemun-gu, Seoul 130-702, Korea e-mail: dichang@khmc.or.kr

J. S. Lee

Department of Biostatistics, Korea University, Seoul, Korea

B. J. Kim

Department of Neurology, Seoul National University Bundang Hospital, Seongnam-si, Gyeonggi-do, Korea maximum right $-0.037 \pm 0.173$ vs. $0.050 \pm 0.200 \mathrm{~mm}$, $p=0.001$; mean left $-0.052 \pm 0.102$ vs. $0.023 \pm 0.112 \mathrm{~mm}$, $p<0.001$; and mean right $-0.038 \pm 0.106$ vs. $0.042 \pm 0.139$ $\mathrm{mm}, p<0.001)$. After matching by propensity score, the improvements in both maximum and mean carotid IMT values in the cilostazol group remained significant. This study shows that cilostazol causes a significant regression in carotid IMT in symptomatic stroke patients.

Keywords Stroke - Carotid intima-media thickness . Atherosclerosis · Cilostazol

\section{Introduction}

Carotid intima-media thickness (IMT) reflects a preclinical state of atherosclerosis and can be used as a risk marker for myocardial infarction and stroke [6]. Vascular outcomes can be predicted using carotid IMT, and increased carotid IMT values are associated with a higher risk of long-term stroke recurrence [21, 33]. Carotid IMT has been used as a surrogate marker for evaluating therapeutic interventions in atherosclerotic disease [3, 26].

Cilostazol, a phosphodiesterase 3 inhibitor, has been shown to be an alternative to aspirin for secondary prevention in patients with non-cardioembolic ischemic stroke $[14,15]$. In addition, cilostazol is suggested to attenuate the increase in carotid IMT in diabetes and coronary patients [1, 16, 24, 28], and it has been reported to prevent the progression of symptomatic intracranial arterial stenosis [18].

In the Cilostazol Against the Progression of carotid Intima-media Thickness in symptomAtic ischemic stroke patients (CAPITA) study, our aim is to assess the effects of cilostazol on the prevention of progression of carotid artery IMT after ischemic stroke. 


\section{Methods}

Subjects and study design

The study design is a hybrid retrospective and prospective study. We retrospectively enrolled symptomatic ischemic stroke or transient ischemic attack (TIA) patients and prospectively obtained follow-up carotid ultrasounds between 12 and 60 months. From January 2005 to June 2009, we identified 1,049 consecutive patients who visited our hospital ( $<7$ days after onset) and who underwent carotid ultrasound.

We excluded subjects who: (1) were younger than 40 or older than 80 years of age; (2) had taken warfarin at discharge; (3) had total internal carotid artery (ICA) occlusion; if the stroke mechanism was (4) cardioembolism or (5) other determined etiologies according to TOAST classification; and (6) if the functional ranking at discharge was greater than 4 on a modified Rankin scale (mRS). After allocation into cilostazol and control groups, additional patients were excluded if they (7) underwent carotid interventions; (8) were lost during follow-up; (9) had not taken medication for more than $80 \%$ of the follow-up period; (10) had taken prohibited concomitant medications such as warfarin, sarpogrelate, beraprost, or mesoglycan; or (11) changed their antiplatelet regimen within the followup period. Additionally, if they refused informed consent or if their mRS was four or greater, they were also excluded. In both groups, we randomly contacted the patients by telephone until we had examined more than 100 patients.

All patients maintained antiplatelet therapy after discharge. In the cilostazol group, we selected patients who had taken between 100 and $200 \mathrm{mg} /$ day cilostazol, and in the control group, antiplatelets were restricted to aspirin (100-300 mg/ day), clopidogrel (75 mg/day), or triflusal (300-900 mg/day), all of which are commonly used in Korea. We did not exclude patients who received additional antiplatelet therapy in the cilostazol group (Supplementary Table 1). The primary endpoint of this study was changes in the mean and maximum common carotid artery IMT (CCA-IMT) between baseline and follow-up. The secondary endpoint was the occurrence of vascular events including ischemic stroke, TIA, acute coronary syndrome, or hemorrhagic stroke and hemorrhage requiring hospital admission and/or transfusion. Laboratory data such as lipid profile, hsCRP, and glycated hemoglobin were also collected.

All subjects provided informed consent, and the study was approved by the institutional review board at our hospital (KMC IRB 0849-02).

\section{Measurement of IMT}

Ultrasonography was performed on the left and right carotid arteries using the GE Logiq 7 Ultrasound System (GE
Medical Systems, Milwaukee, WI, USA) throughout the entire follow-up period. Standardized longitudinal B-mode images with a $12-\mathrm{MHz}$ linear transducer were obtained from the near and far walls of the common carotid arteries. We used the method recommended by Mannheim carotid IMT consensus [32]. However, because the majority of the currently available evidence addressing the assumption of carotid IMT as an indicator of generalized atherosclerosis comes from studies where regular thickening and plaques were included in the IMT measurement, we included IMT (plaques) data if the thickness was greater than $0.5 \mathrm{~mm}$ [23].

Carotid ultrasonography was performed by an expert sonographer who was unaware of the clinical information of the subjects. Baseline carotid ultrasound measurements were performed within a few days after stroke onset, and follow-up measurements were prospectively performed between October 2008 and September 2010 (12-60 months after baseline exam).

To avoid inter-reader variability, all IMT measurements were read by two observers (Hwang $\mathrm{KJ}$ and $\mathrm{Kim} \mathrm{JH}$ ) blinded to the clinical information, using the semi-automated digital innovative measurement software, Intimascope (Media Cross Co. Ltd., Tokyo, Japan) [34]. The IMT was measured as the distance between two parallel lines corresponding to the lumen-intima and media-adventitia interface on the posterior walls of the common carotid arteries. The maximum IMT values of both common carotid arteries (maximum CCA-IMT) and the mean CCAIMT were calculated by Intimascope (Supplementary Fig 1). We adopted the mean values of maximum CCAIMT and mean CCA-IMT read by two independent observers. The interclass correlation coefficients of both maximum CCA-IMT and mean CCA-IMT were 0.812-0.912 (Cronbach's alpha 0.912-0.961).

\section{Statistical analysis}

We assumed that the differences in CCA-IMT between groups would be $0.08 \mathrm{~mm}$ over the 2 years [16, 24]. Therefore, registration of at least 98 patients was required to obtain $80 \%$ power to detect a difference of $0.08 \mathrm{~mm}$ in CCA-IMT, assuming a standard deviation of 0.20 , no dropout, and a 0.05 level of significance. In this study, the target number of enrolled patients was set at 100 for each group.

The baseline demographic, clinical, and laboratory variables were compared using Student's $t$ test or MannWhitney tests for continuous variables and using Pearson's Chi-square test or Fisher's exact tests for categorical ones. Analysis of covariance (ANCOVA) was used to compare the means of primary endpoint between the two groups, with adjustment for potential clinical variables. The 
following potential clinical variables were selected: age, gender, body mass index, stroke subtype, location, previous stroke history, hypertension, diabetes, hyperlipidemia, current smoking, administration of statin, glycated hemoglobin, total cholesterol, high-density lipoprotein (HDL) cholesterol, triglyceride, low-density lipoprotein (LDL) cholesterol, and the interval between baseline and followup carotid ultrasound exam.

Because of the possibility of residual confounding even with multivariable analyses, secondary analyses were performed using a propensity-matched sample. For the propensity score analysis, a multivariable logistic regression model that predicted the cilostazol group was generated. The potential clinical variables were included in the model. The predicted probability of cilostazol group (i.e., propensity score) was then calculated for each patient. A greedy matching algorithm was used to match the cilostazol group's patients with the control group's patients within a caliper of 0.6 $\mathrm{SD}$ of the logit of the propensity score, with a matching ratio of 1:1 [4, 27]. To determine whether the propensity-score approach achieved balance in potential confounders, we assessed absolute standardized differences for each confounder. Thus, evidence of imbalance in potential confounders was identified by examining the reduction in absolute standardized differences. The adequate balance was defined as absolute standardized difference less than 0.1 . In the final propensity-scorematched sample, we compared the primary endpoint between cilostazol and control groups using paired $t$ tests.

All statistical analyses were conducted using SPSS for Windows version 18.0 (SPSS Inc., Chicago, IL, USA) and SAS version 9.2 (SAS Institute, Cary, NC, USA), and the level of significance was accepted at $p<0.05$. All hypothesis tests were two-sided.

\section{Results}

A total of 447 patients were assigned to the cilostazol and control group (132 and 315 patients, respectively). After the exclusion of 31 and 208 patients in the cilostazol and control groups, respectively, the remaining 101 and 107 patients for each group were included in the final analysis (Fig. 1).

The subjects ranged in age from 40 to 78 years (mean $62.5 \pm 8.8$ years). The mean interval between baseline and follow-up exam carotid ultrasound was 2.1 years. There were no significant differences in clinical or laboratory

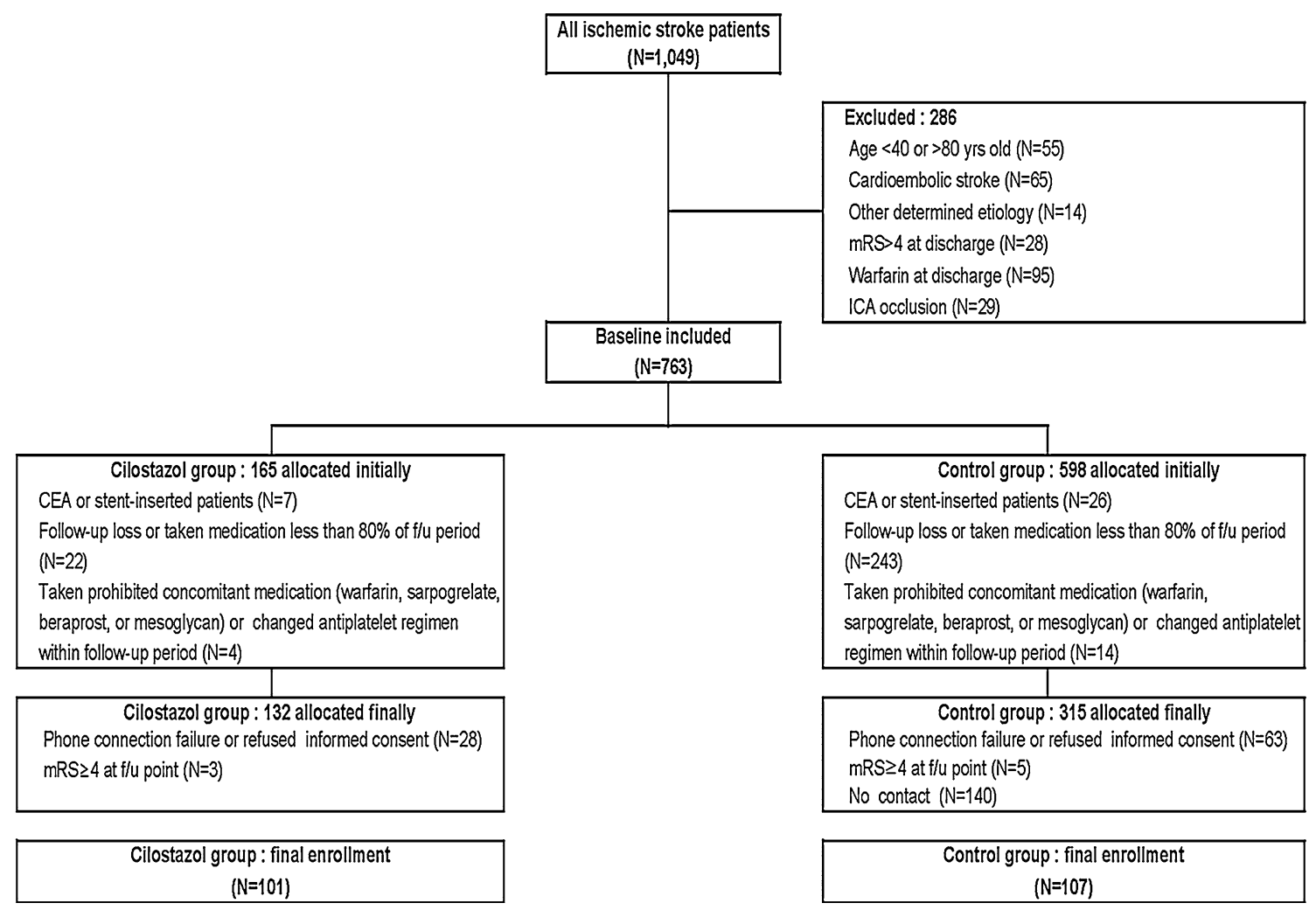

Fig. 1 Disposition of patients and reasons for patient exclusion. $m R S$ modified Rankin scale, ICA internal carotid artery, $C E A$ carotid endarterectomy 
findings between the cilostazol and control groups, except the antiplatelet regimen (Table 1).

\section{Carotid IMT}

Maximum and mean IMTs in the left and right CCAs were reduced significantly in the cilostazol group compared to those in the control group. ANCOVA adjusted for age, gender, stroke subtype, location, previous stroke, hypertension, diabetes, hyperlipidemia, current smoking, statin administration, body mass index, glycated hemoglobin, total cholesterol, HDL cholesterol, triglyceride, LDL cholesterol, and interval showed that cilostazol significantly reduced the maximum and mean CCA-IMTs, whereas other antiplatelets did not (Table 2). In addition, there was a difference between the mean changes of the mean CCAIMTs in low-dose $(100 \mathrm{mg} /$ day $)$ cilostazol subjects and those of control and high-dose (200 mg/day) cilostazol subjects, but it was not consistently significant because of small cases (Supplementary Table 2).

Matched sets by propensity score analyses generated 76 sets of cilostazol and control pairs. Absolute standardized differences were less than $10 \%$ for all covariates, which suggests a successful matching (Fig. 2). After the propensity score matching, the values of both maximum and mean CCAIMTs were also significantly improved in the cilostazol group in comparison with the control group (Table 3).

\section{Other parameters}

We analyzed some laboratory data at baseline and followup. Total cholesterol, LDL cholesterol, and triglyceride were all decreased, while HDL cholesterol were increased in both groups (Table 4). Among the changes of lipid profile between baseline and follow-up, only HDL cholesterol was significantly improved in the two-way ANOVA adjusted for administration of statins $(p=0.006)$.

Ischemic stroke recurrence occurred in four $(4.0 \%)$ and five $(4.7 \%)$ in the cilostazol and control groups, respectively (Table 5).

\section{Discussion}

This is the first case-controlled study investigating the effects of cilostazol for an average of 2.1 years on the progression of carotid IMT in patients with ischemic stroke. Our results reveal that cilostazol may reduce carotid IMT and increase the HDL cholesterol level in ischemic stroke patients.

Ultrasound examination of carotid arteries is a simple and noninvasive method to evaluate early carotid atherosclerosis by measuring IMT or by direct visualization of atherosclerotic plaque. CCA-IMT itself is a more reproducible measure for cardiovascular risk assessment and intervention studies than those at other sites of the carotid artery, so we did not include carotid bifurcation or ICA IMT [32]. It has also been shown that the changes in carotid IMT measurements over time correlate with the occurrence of future cerebrovascular events [33]. However, the subjects in these previous studies were usually healthy patients with diabetes or coronary disease. There is limited data regarding carotid IMT regression trials in ischemic stroke patients $[1,6,16,17,21,24,28,30,31]$. Ischemic stroke patients have a three- to fivefold higher risk of early recurrence if the stroke was caused by small or large artery disease [22]. The study of carotid atherosclerosis in ischemic stroke patients is valuable not only because it has a direct relationship but because it can help in assessing combined systemic atherosclerosis including peripheral artery disease $[5,12]$.

There have been many pharmaceutical trials using lipidlowering drugs such as different kinds of statins and niacin, peroxisome proliferator-activator receptors such as rosiglitazone and pioglitazone, anti-hypertensitivity drugs such as ACE inhibitors, calcium channel antagonists, and $\beta$-blockers, all of which confirm carotid IMT regression $[3,13,19,20,26,29,31]$. However, there have been few studies on the effects of antiplatelet agents on the progression of carotid IMT. Aspirin and ticlopidine (a thienopyridine derivative) have been studied to assess their abilities to attenuate carotid IMT progression [17]. Although the antiplatelet actions are mediated by different mechanisms, these antiplatelets showed low efficacy for attenuating the progression of carotid IMT of type 2 diabetes patients. On the other hand, studies evaluating the effects of cilostazol therapy on carotid IMT revealed nearly complete prevention or a decrease in carotid IMT after 1-2 years of cilostazol treatment $[1,16,24,28]$. The results of these studies indicate that cilostazol is a more potent antiplatelet agent than the others for regression of carotid IMT.

Cilostazol is a different type of antiplatelet agent that inhibits type 3 phosphodiesterase and decreases thromboxane formation by enhancement of the platelet/cAMP level. The increase in cAMP level leads to an inhibition of platelet aggregation, vasodilation, and vascular smooth muscle cell proliferation, an increase in heart rate and contractile force, and an improvement in lipid metabolism $[9,11]$. Because large quantities of phosphodiesterase 3 are found in vascular smooth muscle cells, cilostazol can inhibit smooth muscle cell proliferation. Due to these effects, cilostazol has been consistently shown to reduce coronary restenosis in patients with stent implantation and intracranial arterial stenosis in acute stroke patients with symptomatic middle cerebral artery or basilar artery 
Table 1 Baseline demographics and clinical characteristics of all patients

\begin{tabular}{|c|c|c|c|c|c|}
\hline \multirow[b]{2}{*}{ Gender (male), $n(\%)$} & \multicolumn{2}{|c|}{ Cilostazol $(n=101)$} & \multicolumn{2}{|c|}{ Control $(n=107)$} & \multirow{2}{*}{$\frac{p \text { value }}{0.998}$} \\
\hline & 67 & $(66.3)$ & 71 & $(66.4)$ & \\
\hline Age (years) & 62.76 & \pm 9.04 & 62.26 & \pm 8.58 & $0.682^{\dagger}$ \\
\hline Body mass index, $\mathrm{kg} / \mathrm{m}^{2}$ & 24.47 & \pm 2.95 & 23.92 & \pm 2.65 & $0.161^{\dagger}$ \\
\hline Stroke subtype, $n(\%)$ & & & & & 0.238 \\
\hline LAA & 43 & $(42.6)$ & 37 & $(34.6)$ & \\
\hline SVO & 28 & $(27.7)$ & 40 & $(37.4)$ & \\
\hline Undetermined & 17 & $(16.8)$ & 22 & $(20.6)$ & \\
\hline TIA & 13 & $(12.9)$ & 8 & $(7.5)$ & \\
\hline Location (\%) & & & & & $0.170^{*}$ \\
\hline Anterior circulation & 67 & $(66.3)$ & 59 & $(55.1)$ & \\
\hline Posterior circulation & 33 & $(32.7)$ & 47 & $(43.9)$ & \\
\hline Both & 1 & $(1.1)$ & 1 & $(1.0)$ & \\
\hline Previous stroke, $n(\%)$ & 25 & $(24.8)$ & 19 & $(17.8)$ & 0.217 \\
\hline Hypertension, $n(\%)$ & 77 & $(76.2)$ & 76 & $(71.0)$ & 0.395 \\
\hline Diabetes, $n(\%)$ & 31 & $(30.7)$ & 30 & $(28.0)$ & 0.674 \\
\hline Hyperlipidemia, $n(\%)$ & 39 & $(38.6)$ & 46 & $(43.0)$ & 0.521 \\
\hline Current smoking, $n(\%)$ & 27 & $(26.7)$ & 40 & $(37.7)$ & 0.134 \\
\hline Cilostazol, $n(\%)$ & 101 & $(100.0)$ & 0 & $(0.0)$ & $<0.001$ \\
\hline $100 \mathrm{mg} /$ day & 29 & $(28.7)$ & & & \\
\hline $200 \mathrm{mg} /$ day & 72 & $(71.3)$ & & & \\
\hline Statin, $n(\%)$ & 59 & $(58.4)$ & 59 & $(55.1)$ & 0.634 \\
\hline Admission NIHSS & 3.00 & $(1-4)$ & 3.00 & $(1-4)$ & $0.552^{\S}$ \\
\hline Discharge mRS & & & & & 0.725 \\
\hline 0 & 20 & $(19.8)$ & 19 & $(17.8)$ & \\
\hline 1 & 44 & $(43.6)$ & 42 & $(39.3)$ & \\
\hline 2 & 27 & $(26.7)$ & 30 & $(28.0)$ & \\
\hline 3 & 6 & $(5.9)$ & 12 & $(11.2)$ & \\
\hline 4 & 4 & $(4.0)$ & 4 & (3.7) & \\
\hline Hemoglobin A1c, $(\%)$ & 6.05 & \pm 1.23 & 6.22 & \pm 1.37 & $0.352^{\dagger}$ \\
\hline Total cholesterol (mg/dl) & 188.20 & \pm 41.34 & 190.42 & \pm 37.59 & $0.685^{\dagger}$ \\
\hline HDL cholesterol (mg/dl) & 41.46 & \pm 11.00 & 40.51 & \pm 11.02 & $0.538^{\dagger}$ \\
\hline Triglyceride (mg/dl) & 141.91 & \pm 70.43 & 149.37 & \pm 106.87 & $0.555^{\dagger}$ \\
\hline LDL cholesterol (mg/dl) & 117.41 & \pm 35.68 & 118.07 & \pm 33.82 & $0.890^{\dagger}$ \\
\hline Interval from baseline to follow-up carotid ultrasound (months) & 23.88 & \pm 11.95 & 26.19 & \pm 12.50 & $0.176^{\dagger}$ \\
\hline \multicolumn{6}{|l|}{ Baseline CCA-IMT (mm) } \\
\hline Maximum, left & 1.105 & \pm 0.382 & 1.101 & \pm 0.410 & $0.941^{\dagger}$ \\
\hline Mean, left & 0.863 & \pm 0.232 & 0.855 & \pm 0.242 & $0.825^{\dagger}$ \\
\hline Maximum, right & 1.005 & \pm 0.348 & 1.053 & \pm 0.405 & $0.364^{\dagger}$ \\
\hline Mean, right & 0.801 & \pm 0.206 & 0.822 & \pm 0.229 & $0.482^{\dagger}$ \\
\hline
\end{tabular}

Continuous variables are expressed as mean \pm standard deviation (SD) or median (interquartile range), whereas categorical variables are presented as absolute values and percentages

LAA large artery atherosclerosis, SVO small vessel occlusion, TIA transient ischemic attack, NIHSS NIH Stroke Scale, $m R S$ modified Rankin scale, $W B C$ white blood cell, $H D L$ high-density lipoprotein, $L D L$ low-density lipoprotein, $C C A-I M T$ common carotid artery intima-media thickness

* $p$ values are for Chi-squared test unless indicated

${ }^{\dagger} p$ value is for Student's $t$ test

* $p$ value is for Fisher's exact test

$\S p$ value is for Mann-Whitney test 
Table 2 Changes in mean and maximum CCA-IMT values between baseline and follow-up

\begin{tabular}{|c|c|c|c|c|c|c|c|}
\hline \multirow{2}{*}{ Left maximum CCA-IMT } & \multicolumn{2}{|c|}{ Cilostazol $(n=101)$} & \multicolumn{2}{|c|}{ Control $(n=107)$} & \multirow[t]{2}{*}{ Cronbach's alpha } & \multirow[t]{2}{*}{ ICC } & \multirow{2}{*}{$\frac{p \text { value }}{0.001}$} \\
\hline & & & & & & & \\
\hline Baseline & 1.105 & \pm 0.382 & 1.101 & \pm 0.410 & 0.929 & 0.833 & \\
\hline Follow-up & 1.057 & \pm 0.396 & 1.122 & \pm 0.447 & 0.961 & 0.909 & \\
\hline Mean change & -0.048 & \pm 0.186 & 0.022 & \pm 0.163 & & & \\
\hline Left mean CCA-IMT & & & & & & & $<0.001$ \\
\hline Baseline & 0.863 & \pm 0.232 & 0.855 & \pm 0.242 & 0.934 & 0.851 & \\
\hline Follow-up & 0.810 & \pm 0.220 & 0.879 & \pm 0.278 & 0.958 & 0.912 & \\
\hline Mean change & -0.052 & \pm 0.102 & 0.023 & \pm 0.112 & & & \\
\hline Right maximum CCA-IMT & & & & & & & 0.001 \\
\hline Baseline & 1.005 & \pm 0.348 & 1.053 & \pm 0.405 & 0.919 & 0.815 & \\
\hline Follow-up & 0.968 & \pm 0.313 & 1.103 & \pm 0.489 & 0.923 & 0.840 & \\
\hline Mean change & -0.037 & \pm 0.173 & 0.050 & \pm 0.200 & & & \\
\hline Right mean CCA-IMT & & & & & & & $<0.001$ \\
\hline Baseline & 0.801 & \pm 0.206 & 0.822 & \pm 0.229 & 0.912 & 0.812 & \\
\hline Follow-up & 0.764 & \pm 0.183 & 0.865 & \pm 0.287 & 0.940 & 0.877 & \\
\hline Mean change & -0.038 & \pm 0.106 & 0.042 & \pm 0.139 & & & \\
\hline
\end{tabular}

Values are mean \pm SD. Comparisons of IMTs during treatment with baseline values were performed by ANCOVA adjusted for age, sex, stroke subtype, location, previous stroke, hypertension, diabetes, hyperlipidemia, current smoking, statin, body mass index, glycated hemoglobin, total cholesterol, HDL cholesterol, triglyceride, LDL cholesterol, and interval

ICC intraclass correlation coefficient

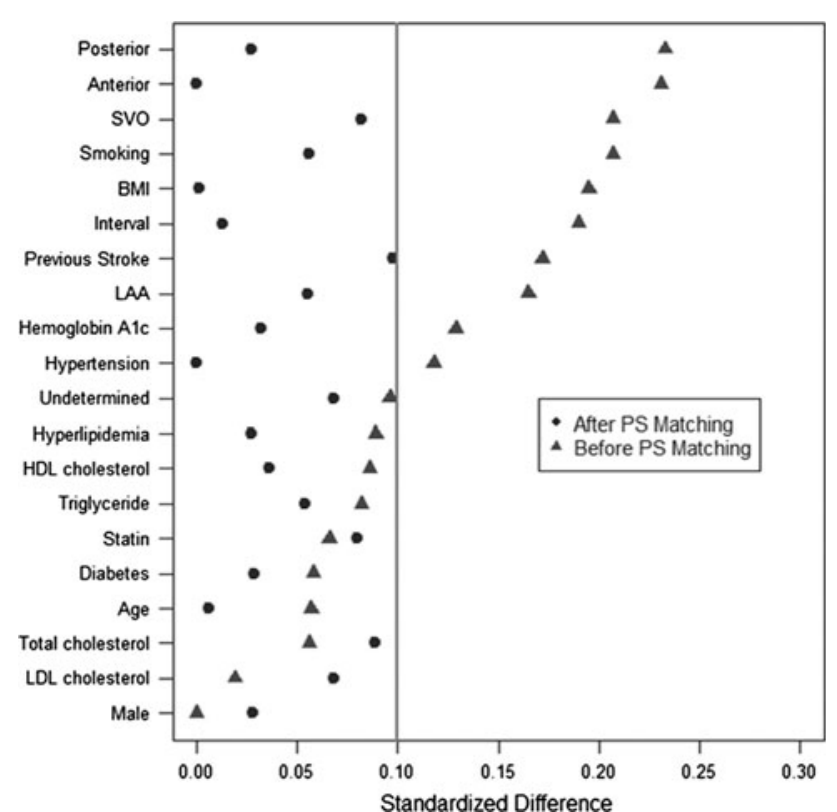

Fig. 2 Absolute standardized differences of covariates before and after propensity score matching. SVO small vessel occlusion, $B M I$ body mass index, $L A A$ large artery atherosclerosis

stenosis [8, 18]. Dipyridamole, a phosphodiesterase 5 inhibitor, also has an antiproliferative effect, and extendedrelease dipyridamole with aspirin (Aggrenox) showed an effect on hemodialysis graft potency [7]. However, Aggrenox is not available in Korea, so we could not directly compare the effects of a phosphodiesterase 3 inhibitor with those of a phosphodiesterase 5 inhibitor in ischemic stroke patients. A few experimental studies have revealed that the inhibition of phosphodiesterase 3 can elicit potent antimitogenic and anti-proliferative activities $[2,11]$.

Although the anti-proliferative mechanism of cilostazol has not yet been established, the beneficial effects on lipoprotein metabolism may play a role in carotid IMT regression. In our study, all lipid profiles and glycated hemoglobin were significantly improved in both groups. This may be caused by the abnormality of baseline laboratory findings in acute stages of ischemic stroke and aggressive treatment of dyslipidemia and diabetes after stroke. Baseline blood tests were performed within 1 week after ischemic stroke, and at the follow-up examination, more than $50 \%$ of all patients were using statins. Nevertheless, the improvement in HDL cholesterol was significantly greater than that in the cilostazol group. Several studies on cilostazol have revealed that the drug can lead to decreases in triglyceride and LDL cholesterol levels and an increase in HDL cholesterol [10, 16, 25]. Previous trials evaluating the use of niacin with statins demonstrated their superiority for IMT regression acquired by an increase in HDL cholesterol rather than a decrease in LDL cholesterol [31]. In our study, no subject received niacin, but an increase in HDL cholesterol by cilostazol yielded an indirect effect on carotid IMT regression. In fact, LDL cholesterol and triglyceride levels may be influenced by 
Table 3 Changes in mean and maximum CCA-IMT values between baseline and follow-up in the matched group

\begin{tabular}{lllllr}
\hline Mean change & $\begin{array}{l}\text { Cilostazol } \\
(n=76)\end{array}$ & $\begin{array}{l}\text { Control } \\
(n=76)\end{array}$ & $p$ value \\
\hline $\begin{array}{l}\text { Left maximum CCA- } \\
\text { IMT }\end{array}$ & -0.050 & \pm 0.188 & 0.020 & \pm 0.172 & 0.012 \\
$\begin{array}{l}\text { Left mean CCA-IMT } \\
\text { Right maximum }\end{array}$ & -0.057 & \pm 0.094 & 0.024 & \pm 0.109 & $<0.001$ \\
$\quad-0.025$ & \pm 0.188 & 0.054 & \pm 0.184 & 0.006 \\
$\quad \begin{array}{l}\text { CCA-IMT } \\
\text { Right mean CCA- }\end{array}$ & -0.033 & \pm 0.104 & 0.050 & \pm 0.130 & $<0.001$ \\
$\quad$ IMT & & & & &
\end{tabular}

Comparisons of IMTs during treatment with baseline values were performed by paired $t$ test

Mean change $=$ follow-up IMT - baseline IMT

cilostazol, but aggressive treatment with statins or fenofibrates to reduce LDL cholesterol or triglyceride level may offset the effect of cilostazol. Because the rates of patients with statin administration were not significantly different, we could not perform further analysis.

Our study does have some limitations. First, our study design was not a randomized controlled trial, and our subjects were recruited from a single center and were thus not representative of the general population. However, demographic findings and initial CCA-IMT values of our subjects were very similar in both groups. Secondary analyses using propensity score matching revealed similar results. In addition, carotid ultrasounds were performed by one sonographer, and the IMT measurements were read by two independent observers blinded to clinical information using semi-automated software. Second, some patients allocated to the cilostazol group have taken other antiplatelets as well as cilostazol. We cannot entirely exclude the possibility that concomitant antiplatelet use in the cilostazol group could influence and weaken the results of our study. However, the prevalence of other antiplatelet use was higher in control group, so that such bias, if any, might not be enough to affect or change our result. Third, the Mannheim consensus recommends that IMT and plaque measurements should be included as secondary endpoints if clinical outcome parameters are defined in the study [32]. However, we did not select clinical outcome as a primary outcome because clinical events including cardiovascular or cerebrovascular attacks and bleeding complication can alter the subject's antiplatelet regimen and hospital followup. To compensate for this weak point, we adopted propensity score matching analysis. Fourth, some patients had plaques in the carotid bifurcation, ICA, and sometimes in the CCA. Further study of the volumetric evaluation of carotid plaque is needed to assess the direct effects of cilostazol on carotid atherosclerosis.

Table 4 Changes in total cholesterol, LDL and HDL cholesterol, and triglycerides between baseline and follow-up

\begin{tabular}{|c|c|c|c|c|c|}
\hline & Cilostazol & & Control & & $p$ value \\
\hline Total cholesterol (mg/dl) & & & & & 0.557 \\
\hline Baseline & 188.20 & \pm 41.34 & 190.42 & \pm 37.59 & \\
\hline Follow-up & 169.11 & \pm 35.53 & 167.69 & \pm 35.30 & \\
\hline Mean change & -21.53 & \pm 43.01 & -23.17 & \pm 48.95 & \\
\hline HDL cholesterol (mg/dl) & & & & & 0.006 \\
\hline Baseline & 41.46 & \pm 11.00 & 40.51 & \pm 11.02 & \\
\hline Follow-up & 53.86 & \pm 15.00 & 46.95 & \pm 12.95 & \\
\hline Mean change & 11.50 & \pm 15.59 & 6.29 & \pm 10.82 & \\
\hline Triglyceride (mg/dl) & & & & & 0.212 \\
\hline Baseline & 141.91 & \pm 70.43 & 149.37 & \pm 106.87 & \\
\hline Follow-up & 113.63 & \pm 54.23 & 141.76 & \pm 77.92 & \\
\hline Mean change & -29.85 & \pm 65.23 & -9.94 & \pm 105.99 & \\
\hline LDL cholesterol (mg/dl) & & & & & 0.838 \\
\hline Baseline & 117.40 & \pm 35.68 & 118.08 & \pm 33.82 & \\
\hline Follow-up & 97.24 & \pm 31.40 & 100.83 & \pm 31.83 & \\
\hline Mean change & -21.00 & \pm 35.07 & -17.19 & \pm 42.56 & \\
\hline $\mathrm{HbA1c}(\%)$ & & & & & 0.750 \\
\hline Baseline & 6.05 & \pm 1.23 & 6.22 & \pm 1.37 & \\
\hline Follow-up & 6.31 & \pm 0.93 & 6.51 & \pm 1.38 & \\
\hline Mean change & 0.13 & \pm 1.18 & 0.19 & \pm 1.21 & \\
\hline
\end{tabular}

$p$ value by two-way ANOVA adjusted for administration of statins 
Table 5 Clinical outcomes during the observation period in both groups

\begin{tabular}{llll}
\hline & $\begin{array}{l}\text { Cilostazol } \\
(n=101)\end{array}$ & $\begin{array}{l}\text { Control } \\
(n=107)\end{array}$ & $p$ value* \\
\hline $\begin{array}{l}\text { Ischemic stroke } \\
\begin{array}{l}\text { Transient ischemic } \\
\text { attack }\end{array}\end{array}$ & $4(4.0 \%)$ & $5(4.7 \%)$ & $>0.999$ \\
$\begin{array}{l}\text { Angina or myocardial } \\
\text { infarction }\end{array}$ & $6(5.9 \%)$ & $1(0.9 \%)$ & 0.059 \\
$\begin{array}{l}\text { Major bleeding } \\
\text { a }\end{array}$ & $0(0.0 \%)$ & $1(0.9 \%)$ & $>0.999$ \\
\hline
\end{tabular}

* $p$ values are for Fisher's exact test

${ }^{a}$ Hemorrhagic stroke and hemorrhage requiring hospital admission and/or transfusion

Our results indicate that cilostazol is more beneficial to the regression of carotid IMT in symptomatic ischemic stroke patients than are other antiplatelet agents. In addition, cilostazol can increase serum HDL cholesterol level and can reduce atherosclerotic proliferation. This suggests that cilostazol is a powerful therapeutic agent for controlling carotid atherosclerosis in ischemic stroke patients.

Acknowledgments We especially thank Jae-Eun Kang for her valuable help in data collection and So-Youn Choi for her devoted efforts to finish all carotid ultrasound examinations. This study was supported by the Korea Otsuka Pharmaceutical Company. The analyses and interpretations of the data and the final content of the article were produced independent of the financial sponsors.

Conflicts of interest Dr. S.H. Heo, Dr. J.S. Lee, Dr B.J. Kim, Dr. K.J. Hwang, Dr. J.-H. Kim, and Dr. D.-I. Chang report no disclosures.

Ethical standard All subjects provided informed consent. The study has been approved by the institutional review board at our hospital (KMC IRB 0849-02), and have therefore been performed in accordance with the ethical standards laid down in the 1964 Declaration of Helsinki.

Open Access This article is distributed under the terms of the Creative Commons Attribution License which permits any use, distribution, and reproduction in any medium, provided the original author(s) and the source are credited.

\section{References}

1. Ahn CM, Hong SJ, Park JH, Kim JS, Lim DS (2010) Cilostazol reduces the progression of carotid intima-media thickness without increasing the risk of bleeding in patients with acute coronary syndrome during a 2-year follow-up. Heart Vessels 26:502-510

2. Aizawa T, Wei H, Miano JM, Abe J, Berk BC, Yan C (2003) Role of phosphodiesterase 3 in NO/cGMP-mediated antiinflammatory effects in vascular smooth muscle cells. Circ Res 93:406-413

3. Amarenco P, Labreuche J, Lavallee P, Touboul PJ (2004) Statins in stroke prevention and carotid atherosclerosis: systematic review and up-to-date meta-analysis. Stroke 35:2902-2909
4. Austin PC, Grootendorst P, Anderson GM (2007) A comparison of the ability of different propensity score models to balance measured variables between treated and untreated subjects: a Monte Carlo study. Stat Med 26:734-753

5. Cacoub PP, Abola MT, Baumgartner I, Bhatt DL, Creager MA, Liau CS, Goto S, Rother J, Steg PG, Hirsch AT (2009) Cardiovascular risk factor control and outcomes in peripheral artery disease patients in the reduction of atherothrombosis for continued health (REACH) registry. Atherosclerosis 204:e86-e92

6. Chambless LE, Folsom AR, Clegg LX, Sharrett AR, Shahar E, Nieto FJ, Rosamond WD, Evans G (2000) Carotid wall thickness is predictive of incident clinical stroke: the atherosclerosis risk in communities (ARIC) study. Am J Epidemiol 151:478-487

7. Dixon BS, Beck GJ, Vazquez MA, Greenberg A, Delmez JA, Allon M, Dember LM, Himmelfarb J, Gassman JJ, Greene T, Radeva MK, Davidson IJ, Ikizler TA, Braden GL, Fenves AZ, Kaufman JS, Cotton JR Jr, Martin KJ, McNeil JW, Rahman A, Lawson JH, Whiting JF, Hu B, Meyers CM, Kusek JW, Feldman HI (2009) Effect of dipyridamole plus aspirin on hemodialysis graft patency. N Engl J Med 360:2191-2201

8. Douglas JS Jr, Holmes DR Jr, Kereiakes DJ, Grines CL, Block E, Ghazzal ZM, Morris DC, Liberman H, Parker K, Jurkovitz C, Murrah N, Foster J, Hyde P, Mancini GB, Weintraub WS (2005) Coronary stent restenosis in patients treated with cilostazol. Circulation 112:2826-2832

9. Dzau VJ, Braun-Dullaeus RC, Sedding DG (2002) Vascular proliferation and atherosclerosis: new perspectives and therapeutic strategies. Nat Med 8:1249-1256

10. Elam MB, Heckman J, Crouse JR, Hunninghake DB, Herd JA, Davidson M, Gordon IL, Bortey EB, Forbes WP (1998) Effect of the novel antiplatelet agent cilostazol on plasma lipoproteins in patients with intermittent claudication. Arterioscler Thromb Vasc Biol 18:1942-1947

11. Feijge MA, Ansink K, Vanschoonbeek K, Heemskerk JW (2004) Control of platelet activation by cyclic AMP turnover and cyclic nucleotide phosphodiesterase type-3. Biochem Pharmacol 67:1559-1567

12. Flu WJ, van Kuijk JP, Hoeks SE, Kuiper R, Schouten O, Goei D, Winkel T, van Gestel YR, Verhagen HJ, Bax JJ, Poldermans D (2009) Intima media thickness of the common carotid artery in vascular surgery patients: a predictor of postoperative cardiovascular events. Am Heart J 158:202-208

13. Hedblad B, Wikstrand J, Janzon L, Wedel H, Berglund G (2001) Low-dose metoprolol CR/XL and fluvastatin slow progression of carotid intima-media thickness: main results from the betablocker cholesterol-lowering asymptomatic plaque study (BCAPS). Circulation 103:1721-1726

14. Huang Y, Cheng Y, Wu J, Li Y, Xu E, Hong Z, Li Z, Zhang W, Ding M, Gao X, Fan D, Zeng J, Wong K, Lu C, Xiao J, Yao C (2008) Cilostazol as an alternative to aspirin after ischaemic stroke: a randomised, double-blind, pilot study. Lancet Neurol 7:494-499

15. Kamal AK, Naqvi I, Husain, Khealani BA (2011) Cilostazol versus aspirin for secondary prevention of vascular events after stroke of arterial origin. Cochrane Database Syst Rev 19:CD008076

16. Katakami N, Kim YS, Kawamori R, Yamasaki Y (2010) The phosphodiesterase inhibitor cilostazol induces regression of carotid atherosclerosis in subjects with type 2 diabetes mellitus: principal results of the diabetic atherosclerosis prevention by cilostazol (DAPC) study: a randomized trial. Circulation 121:2584-2591

17. Kodama M, Yamasaki Y, Sakamoto K, Yoshioka R, Matsuhisa M, Kajimoto Y, Kosugi K, Ueda N, Hori M (2000) Antiplatelet drugs attenuate progression of carotid intima-media thickness in subjects with type 2 diabetes. Thromb Res 97:239-245 
18. Kwon SU, Cho YJ, Koo JS, Bae HJ, Lee YS, Hong KS, Lee JH, Kim JS (2005) Cilostazol prevents the progression of the symptomatic intracranial arterial stenosis: the multicenter double-blind placebo-controlled trial of cilostazol in symptomatic intracranial arterial stenosis. Stroke 36:782-786

19. Langenfeld MR, Forst T, Hohberg C, Kann P, Lubben G, Konrad T, Fullert SD, Sachara C, Pfutzner A (2005) Pioglitazone decreases carotid intima-media thickness independently of glycemic control in patients with type 2 diabetes mellitus: results from a controlled randomized study. Circulation 111:2525-2531

20. Lonn E, Yusuf S, Dzavik V, Doris C, Yi Q, Smith S, Moore-Cox A, Bosch J, Riley W, Teo K (2001) Effects of ramipril and vitamin $\mathrm{E}$ on atherosclerosis: the study to evaluate carotid ultrasound changes in patients treated with ramipril and vitamin $\mathrm{E}$ (SECURE). Circulation 103:919-925

21. Lorenz MW, Markus HS, Bots ML, Rosvall M, Sitzer M (2007) Prediction of clinical cardiovascular events with carotid intimamedia thickness: a systematic review and meta-analysis. Circulation 115:459-467

22. Lovett JK, Coull AJ, Rothwell PM (2004) Early risk of recurrence by subtype of ischemic stroke in population-based incidence studies. Neurology 62:569-573

23. Meijer R, Grobee DE, Bots ML (2006) Mannheim consensus on carotid intima-media thickness: opposite and complementary points of view. Cerebrovasc Dis 21:415-416

24. Mitsuhashi N, Tanaka Y, Kubo S, Ogawa S, Hayashi C, Uchino H, Shimizu T, Watada H, Kawasumi M, Onuma T, Kawamori R (2004) Effect of cilostazol, a phosphodiesterase inhibitor, on carotid IMT in Japanese type 2 diabetic patients. Endocr $\mathrm{J}$ $51: 545-550$

25. Nakamura N, Hamazaki T, Johkaji H, Minami S, Yamazaki K, Satoh A, Sawazaki S, Urakaze M, Kobayashi M, Osawa H, Yamabe H, Okomura K (2003) Effects of cilostazol on serum lipid concentrations and plasma fatty acid composition in type 2 diabetic patients with peripheral vascular disease. Clin Exp Med 2:180-184

26. Riccioni G (2009) Statins and carotid intima-media thickness reduction: an up-to-date review. Curr Med Chem 16:1799-1805
27. Rosenbaum PR (1995) Observational studies. Springer, New York

28. Shinoda-Tagawa T, Yamasaki Y, Yoshida S, Kajimoto Y, Tsujino T, Hakui N, Matsumoto M, Hori M (2002) A phosphodiesterase inhibitor, cilostazol, prevents the onset of silent brain infarction in Japanese subjects with type II diabetes. Diabetologia 45:188-194

29. Sidhu JS, Kaposzta Z, Markus HS, Kaski JC (2004) Effect of rosiglitazone on common carotid intima-media thickness progression in coronary artery disease patients without diabetes mellitus. Arterioscler Thromb Vasc Biol 24:930-934

30. Stein JH, Korcarz CE, Hurst RT, Lonn E, Kendall CB, Mohler ER, Najjar SS, Rembold CM, Post WS (2008) Use of carotid ultrasound to identify subclinical vascular disease and evaluate cardiovascular disease risk: a consensus statement from the American Society of Echocardiography Carotid Intima-media Thickness Task Force. Endorsed by the Society for Vascular Medicine. J Am Soc Echocardiogr 21:93-111 (quiz 189-190)

31. Taylor AJ, Villines TC, Stanek EJ, Devine PJ, Griffen L, Miller M, Weissman NJ, Turco M (2009) Extended-release niacin or ezetimibe and carotid intima-media thickness. N Engl J Med 361:2113-2122

32. Touboul PJ, Hennerici MG, Meairs S, Adams H, Amarenco P, Desvarieux M, Ebrahim S, Fatar M, Hernandez-Hernandez R, Kownator S, Prati P, Rundek T, Taylor A, Bornstein N, Csiba L, Vicaut E, Woo KS, Zannad F (2004) Mannheim intima-media thickness consensus. Cerebrovasc Dis 18:346-349

33. Tsivgoulis G, Vemmos K, Papamichael C, Spengos K, Manios E, Stamatelopoulos K, Vassilopoulos D, Zakopoulos N (2006) Common carotid artery intima-media thickness and the risk of stroke recurrence. Stroke 37:1913-1916

34. Yanase T, Nasu S, Mukuta Y, Shimizu Y, Nishihara T, Okabe T, Nomura M, Inoguchi T, Nawata H (2006) Evaluation of a new carotid intima-media thickness measurement by B-mode ultrasonography using an innovative measurement software, Intimascope. Am J Hypertens 19:1206-1212 